\title{
Numerical investigation of crack growth in AISI type 316LN stainless steel weld joint using GTN damage model
}

\author{
N. Sai Deepak*, C. Lakshmana Rao, \\ S.A. Krishnan, G. Sasikala and \\ Raghu V. Prakash
}

Department of Applied Mechanics, Indian Institute of Technology Madras, Chennai - 600036, India Email: sai.deepak13@gmail.com

Email: lakshman@iitm.ac.in Email: sakrish@igcar.gov.in Email: gsasi@igcar.gov.in Email: raghuprakash@iitm.ac.in *Corresponding author

\begin{abstract}
Ductile crack growth in austenitic 316LN stainless steel weld joint has been studied using FEA simulations with Gurson-Tvergaard-Needleman (GTN) damage model. The material specific GTN damage parameters are assessed and calibrated based on coupled experimental and numerical simulations for tensile and compact tension specimens. The influence of initial crack tip at various locations across the weld thickness has been analysed using CT geometry. The simulated results reveal that the crack propagates along the initial crack line for centrally located welds and deviates from the crack line for interfacial welds. The crack growth path for all cases is explained with damage parameters like equivalent plastic strain and void volume fraction.
\end{abstract}

Keywords: 316LN SS weld joint; structural integrity; interface cracks propagation behaviour; finite element analysis; Gurson-Tvergaard-Needleman damage model; equivalent plastic strain; void volume fraction.

Reference to this paper should be made as follows: Sai Deepak, N., Rao, C.L., Krishnan, S.A., Sasikala, G. and Prakash, R.V. (2019) 'Numerical investigation of crack growth in AISI type 316LN stainless steel weld joint using GTN damage model', Int. J. Materials and Structural Integrity, Vol. 13, Nos. 1/2/3, pp.125-143.

Biographical notes: N. Sai Deepak is a Master's (by research) student of Department of Applied Mechanics, Indian Institute of Technology, Madras. He received his Bachelor's in Aeronautical Engineering, Hindustan University. His research interests include fracture mechanics, metal plasticity, and finite element analysis.

C. Lakshmana Rao is a Professor of Department of Applied Mechanics, Indian Institute of Technology, Madras. He received his $\mathrm{ScD}$ from the Massachusetts Institute of Technology, Cambridge in USA. He obtained his Master's in Ocean Engineering and Bachelor's in Civil Engineering from the Indian Institute of Technology, Madras. He has authored or co-authored four books. His research interests include fracture assessment of structures, impact and blast resistance, sealing technology and characterisation of smart material. 
S.A. Krishnan is working as a Scientific Officer in Materials Mechanics Section of Materials Engineering Group at the Indira Gandhi Centre for Atomic Research, Kalpakkam. He has obtained his Master's in Mechanical Engineering from the Delhi College of Engineering, Delhi University and currently pursuing his PhD in Fracture Mechanics at the HBNI. He has several publications in international journals and presentations at international conferences. $\mathrm{He}$ is currently working in the field of mechanics of materials, constitutive modelling for deformation behaviour of materials, high strain rate deformation, ductile and brittle fracture, continuum damage modelling, specimen and component level testing, and fracture transferability studies for fast breeder reactor materials.

G. Sasikala is the Head in Materials Development and Technology Division of Materials Engineering Group at the Indira Gandhi Centre for Atomic Research, Kalpakkam. She is also the Dean in Engineering Sciences, Homi Bhabha National Institute at the Kalpakkam. She has obtained her $\mathrm{PhD}$ in Creep Deformation and Fracture Behaviour of Reactor Materials from the University of Madras. She has made outstanding R\&D contributions in the field of high-temperature deformation, creep and fatigue crack growth, fracture behaviour of reactor materials and welds, damage mechanics and creep life prediction. She has developed novel experimental analysis techniques for fracture properties evaluation. She has published about 150 research papers in international journals and conferences. Her current research of interests include fracture, damage mechanics in quasi-static and dynamic loading conditions, creep and fatigue crack growth studies for fast breeder reactor and advanced ultra super critical power plant materials.

Raghu V. Prakash is a Professor of Department of Mechanical Engineering, Indian Institute of Technology, Madras. He obtained his Master's (by research) and $\mathrm{PhD}$ from the Department of Mechanical Engineering, Indian Institute of Science, Bengaluru. He has developed test systems for use in academia, R\&D and industry during his tenure as a Technical Director at BiSS Research, Bengaluru and teaches courses relating to fracture mechanics, design with advanced materials and product design at IIT Madras. His specialisations include in the areas of fatigue, fracture of materials (metals, composites, and hybrids), structural integrity assessment, remaining life prediction of critical components used in transportation, energy sectors, apart from new product design.

This paper is a revised and expanded version of a paper entitled 'Numerical investigation of ductile damage in a similar weld joint' presented at Indian Conference on Applied Mechanics (INCAM) 2017, MNNIT Allahabad, Uttar Pradesh, India, 5-7 July 2017.

\section{Introduction}

Welding is a dominant method of metal joining process adopted in the fabrication of pressure vessels and piping systems for thermal, nuclear and chemical industries. The fast breeder reactor being commissioned at Kalpakkam involves a large number of weld joints, and many components are fabricated from 316LN SS and welds. Weld joints are prone to have flaws/defects due to expansion/shrinkage of weld metal (WM) (Kumar, 2014). Further, there is a significant plastic strain gradient observed in these welds arising 
from temperature gradient due to multiple passes in welding process (Vijayanand et al., 2017; Muránsky et al., 2015). The fracture assessment of such welds is an essential aspect of structural integrity assessment of the load-bearing structures.

Under small-scale yielding, the ductile tearing resistance of materials is conventionally characterised by a J-resistance $\left(\mathrm{J}_{\mathrm{R}}\right)$ curve (Rice and Rosengren, 1968; Hutchinson, 1968; Rice et al., 1973). The fracture resistance curves characterise the material behaviour and represent the resistance to both stable and unstable crack propagation of a loaded specimen under static boundary conditions. Fracture resistance curves are defined using fracture parameters like $K, J$ or CTOD and expressed as a function of crack extension $(\Delta \mathrm{a}) . J-\Delta \mathrm{a}$ curve is plotted by conducting tests on fracture specimens such as compact tension (CT) specimens using standard and constrained methods (ASTM E1820-17). The present structural integrity assessment procedure for pressure holding components targets at estimating the crack driving force and a measure of fracture toughness for homogenous materials (Kumar et al., 1981; R6, 1998). However, tests performed on various specimens with different geometries and loading conditions revealed that different slopes in $\mathrm{J}_{\mathrm{R}}$ curve are possible for different geometries (Clausmeyer et al., 1991), which raises the question of transferring fracture parameters from specimens to components. It has been found that the $J_{R}$ curves are profoundly influenced by crack tip stress fields (Schuler et al., 1994). $J_{R}$ curves of welded structures are affected by the yield strength mismatch between base metal (BM) and WM and also by the weld geometry (Kocak and Es-Souni, 1989; Kirk and Dodd's, 1993; Michiba et al., 1994). Thus, an important issue to consider in fracture assessment is the incorporation of constraint effects and materials mismatch effects in the evaluation of resistance to the crack propagation in cracked structures. In homogenous specimens, $J-Q$ and $J-T$ two parameters analysis (O'Dowd and Shih, 1991, 1992; Williams, 1957) are used to quantify the level of crack tip constraints. Similar to $J-Q$ and $J-T$ two parameters analysis, a three-parameter analysis such as $J-Q-M$ (Zhang et al., 1996, 1997a, 1997b) and $J-T_{g}-T_{m}$ (Betegón and Peñuelas, 2006) formulations for the crack tip stress field is established. These formulations independently quantify the effects of strength mismatch and weld width in weld joints.

To solve the issues on transferring the fracture parameters from specimens to components and to incorporate the effects of material constraint, an alternative approach for the fracture assessment is introduced which is based on continuum damage mechanics (Chhibber et al., 2011). This local approach involves the simulation of crack growth during failure, by using constitutive models developed based on the estimation of microscopic rupture processes. Such approach aims at modelling the damage due to ductile tearing in three stages:

1 nucleation

2 growth

3 coalescence of voids.

Thus, such models (also called micromechanical models) can consider the constraints effects since stress state at a material failure point is accounted in the model. Hence, these models capture the physical effects of constraints on fracture resistance implicitly. With the increase in plastic strain, local degradation of material occurs, and material completely loses its load bearing capacity leading to crack initiation and propagation. 
This phenomenon is characterised by a critical value of damage parameter $D_{c}$ over a characteristic length $l_{c}$. The ductile failure process for porous materials is modelled using well known micro-mechanical models such as Gurson (1977) model, and Rousselier's (1987) model. Both these models consider void volume fraction (VVF) $f$ as an internal variable of the material and introduce $f$ in the yield function. Rousselier proposed the continuum theory to model void growth alone; hence in practise, it is coupled with void initiation model. Gurson (1977) model is one of the most powerful models and is successfully used by many researchers around the world. This constitutive model introduced by Gurson and modified by Tvergaard and Needleman (1984) consider void initiation, growth, and coalescence with the increase in plastic strain. The required micro-mechanical parameters are obtained from simple tensile tests of notched and smooth specimens, the metallographic study of the tested specimens, and numerical simulations trails based on experimental results of smooth, notched and CT specimens (Samal et al., 2009).

GTN model (1984) has been widely used in simulating the ductile crack initiation and crack growth studies of several specimens. Fracture resistance behaviour using GTN model for different specimens (Østby et al., 2007), material interfaces (Nègre et al., 2005), similar metal weld joints (Chhibber et al., 2011; Rakin et al., 2008; Nègre et al., 2005) and dissimilar metal weld joints (DMWJ) (Wang et al., 2011; Qian Guo et al., 2015) establish a good agreement with experimental findings. A method is proposed (Chhibber et al., 2011) to find modified GTN parameters using numerical fitting according to macroscopic fracture behaviour. This method involves experiments and numerical analysis (called hybrid analysis) of smooth, notched and CT specimens of the materials. This method can specify GTN parameters from a practical angle for the best prediction of fracture process without having much knowledge of the microstructural properties. This method is used (Wang et al., 2011) to perform the fracture study of the DMWJ composed of four materials in the primary system of nuclear power plants. In their study, the comparison between numerical and experimental results showing the predictions made using GTN model on single edge notch specimen of different material joints with different crack locations was performed and successful in matching experiments. This approach of finding GTN model parameters using FEM numerical simulation may need to be further correlated with more simulation and experimental studies.

In this work, the finite element analysis based on GTN model is used to investigate the ductile crack growth behaviour in CT specimens of AISI 316LN SS weld joints. In this study, modified GTN model developed by Tvergaard and Needleman is used. The present work is aimed to study the fracture behaviour of the 316LN SS weld joints. The GTN model has been implemented in the Abaqus FEM software, and this FEM software package is found more efficient (Giglio et al., 2013) and has excellent nonlinear solving capabilities (Qian Guo et al., 2015) and hence this tool is widely used to simulate and predict the ductile crack propagation. The study is structured in five sections. In the introductory section, a brief idea on addressing transferability and material constraints issues on fracture parameters using fracture mechanics and continuum damage models are discussed. The details on the materials and specimen geometry, GTN model and its parameters and FEM model are discussed in Section 2. Section 3 describes the simulation results, including load vs. COD curves and path of the crack in the weld joint. A discussion on the effect of different crack locations and $J-\Delta$ a resistance curves are provided in Section 4. Section 5 provides the conclusions of the present investigation. 


\section{Numerical simulation procedures}

\subsection{Material and geometry of the weld joint}

The material studied is the austenite stainless steel grade 316LN (316LN SS), used for the primary and secondary sodium systems of prototype fast breeder reactor (PFBR). 316LN SS ensures freedom from sensitisation during welding and inter-granular corrosion of the components and provides required material properties like high thermal conductivity, low solidification temperature, elastic and plastic properties. Shield metal arc welding is performed to fabricate $316 \mathrm{LN}$ SS weld joints. In this process, SS 316L electrode sticks are used. Tensile specimens used for material properties testing are extracted perpendicular to the weld seam. In this study, weldment material properties are assumed to be isotropic.

Figure 1 (a) True stress and strain curves: BM and WM (b) CT specimen geometry and initial crack location (see online version for colours)
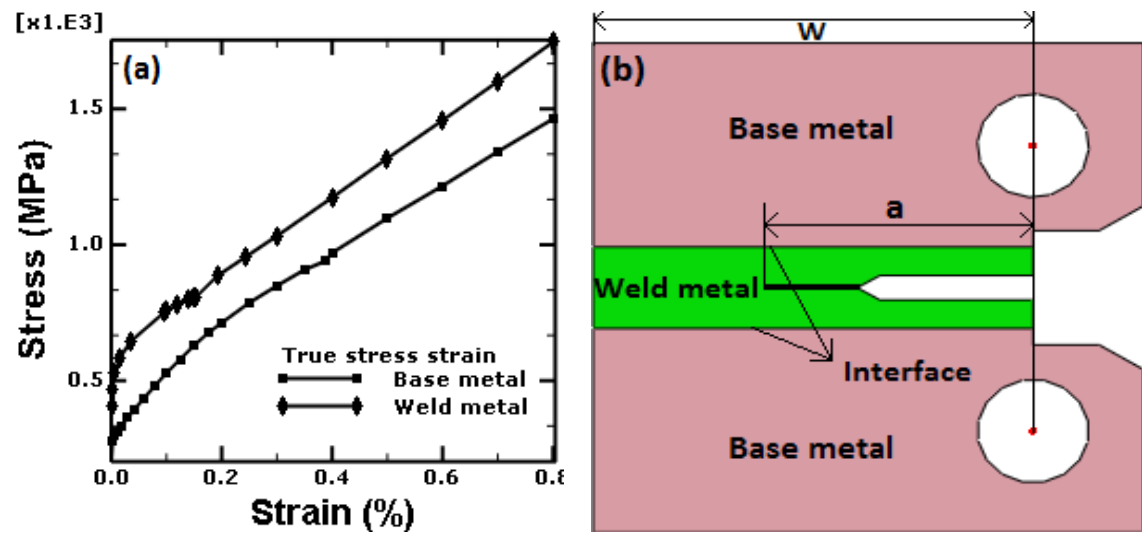

The true stress vs. strain curves of BM and WM of 316LN SS are shown in Figure 1(a). The CT specimen is used to study the fracture behaviour of 316LN SS weld joint. The main dimensions of the CT specimen are shown in Figure 1(b), where the width $\mathrm{W}$ is 50 $\mathrm{mm}$, thickness B is $14 \mathrm{~mm}$, weld width is $14 \mathrm{~mm}$. Size of the heat affected zone (HAZ) is found to be less than $3 \mu \mathrm{m}$. Since the mechanical properties of HAZ and weld are assumed to be similar (Ganesh Kumar et al., 2015) and HAZ is considered to be a part of the weld zone.

\subsection{GTN damage model and parameter estimations}

Ductile fracture in metals is a result of void nucleation, growth and coalescence of the existing and newly born microvoids due to loading. Unlike traditional plasticity models, Gurson (1977) developed a microscopic yield criterion for homogenous, rigid plastic material behaviour which considers ' $f$ ' as an internal variable and captures the degradation of the load-bearing capacity of the material in the presence of porosity. Modified Gurson model (also called GTN model) was developed by Tvergaard and Needleman (1984) to model the interaction between voids and coalescence of voids during the final stage of material failure. The modified GTN model consists of additional 
parameters $\left(q_{1}, q_{2}, q_{3}\right)$ and modified damage variable $f^{*}$. The yield function of the GTN model is shown below:

$$
\phi(\sigma, f, \bar{\sigma})=\frac{\sigma_{e q}^{2}}{\bar{\sigma}}+2 q_{1} f^{*} \cdot \cosh \left(\frac{3}{2} q_{2} \frac{\sigma_{m}}{\bar{\sigma}}\right)-1-\left(q_{1} f^{*}\right)^{2}=0
$$

with $f^{*}=f$ for $f \leq f_{c}$.

$$
=f_{c}+\frac{f_{u}^{*}-f_{c}}{f_{f}-f_{c}}\left(f-f_{c}\right) \text { for } f>f_{c}
$$

where $\sigma_{e q}$ is the von Mises equivalent stress, $\sigma_{m}$ is the hydrostatic stress and $\bar{\sigma}$ is the flow strength of the matrix material which is a function of the accumulated plastic strain. The constitutive model parameters $q_{1}, q_{2}$, and $q_{3}$ are introduced to consider the interaction between adjacent voids. These phenomenological-based parameters depend on the elastic-plastic properties of the material like strain hardening exponent and the yield stress. VVF $(f)$ is the ratio of the volume of voids to the volume of the matrix material. $f_{0}$ is the initial VVF of the material, and void nucleation happens when $f$ reaches $f_{N}$. Both $f_{0}$ and $f_{N}$ parameters are determined based on the metallographic and fracture toughness analysis. Other void nucleation parameters are mean strain at nucleation $\in_{n}$ and corresponding standard deviation $S_{N}$. GTN model considers $f^{*}$ over $f$ to take into account the gradual loss of stress carrying capacity of the material due to void coalescence. When $f$ reaches critical VVF $f_{c}$, void coalescence happens in the materials, and material point loses its load bearing capacity fully, and when $f$ reaches final volume fraction $f_{F}$ or when $f^{*}=f_{u}^{*}$ fracture occurs, where $f_{u}^{*}=1 / q_{1}$. Tvergaard and Needleman (1984) can be referred to explore the equations of the GTN model further. The GTN model is available in Abaqus explicit FEA and is widely used to simulate and predict the ductile fracture process (Wang et al., 2011; Qian Guo et al., 2015).

Among nine parameters of the GTN model parameters, for medium strength steel, GTN constitutive model parameters used by Faleskog et al. (1998) are $q_{1}=1.5, q_{2}=1$ and $q_{3}=2.25$. Void nucleation parameters $\in_{n}=0.3$ and $S_{N}=0.1$ proposed by Kami et al. (2015) have been used in most investigations, and these values are used in this study. The damage parameters $f_{0}, f_{N}, f_{c}$, and $f_{F}$ are typically evaluated by fitting numerical simulations and experimental results. The GTN model parameters for 316LN SS (BM) has been obtained from the literature (Wang et al., 2011). For welded 316LN SS, numerous sets of $f_{0}, f_{N}$, and $f_{F}$ are tried in the simulation process to fit the experimental material response of the tensile specimen and CT specimen. The experiments are carried at IGCAR. Fracture test on CT specimen is performed concerning ASTM E1820. The specimen is fatigue pre-cracked using the RUMUL machine. The fatigue crack tip is placed in the weld. During pre-cracking, the crack growth is monitored using magnification lens. The even growth on both sides is ensured by swap-over the specimen intermittently. The direct current potential drop (DCPD) values are measured before and after fatigue pre-cracking to validate visually observed crack growth in the specimen. The experimental data of the welds used in this work is not stress relieved. Tensile specimen and CT specimen are modelled using experiment specimen dimensions to perform FEA and element mesh size is selected based on the distance between inclusions called characteristic length $\left(l_{c}\right)$ for $316 \mathrm{LN}$ material (Besson et al., 2004). To start with, an initial set of GTN damage parameters are set to BM $316 \mathrm{LN}$ SS. The influence of each 
parameter on the material behaviour of the specimen is studied. The influence of $f_{0}$ is high on the response of the material to GTN damage model. In the process of finding GTN parameters like $f_{N}, f_{c}$, and $f_{F}$, etc., for WM, it is considered to change one parameter value each time and keep other GTN parameters unchanged. It is found that the simulated material response is almost identical and hence GTN damage parameters are dependent on each other (Chhibber et al., 2011). Hence various sets of $f_{c}$ and $f_{N}$ along with $f_{F}$ are studied to match the material response of WM with experimental results of the tensile specimen and CT specimen. The finally determined GTN damage model parameters for $\mathrm{BM}$ and $\mathrm{WM}$ are listed in Table 1 and these parameters are used in the numerical simulation of CT specimens in Section 3.

Table 1 GTN parameters of 316LN SS BM and WM

\begin{tabular}{lccccccccc}
\hline Materials & $q_{1}$ & $q_{2}$ & $q_{3}$ & $f_{0}$ & $\epsilon_{n}$ & $S_{N}$ & $f_{N}$ & $f_{c}$ & $f_{F}$ \\
\hline Base metal & 1.5 & 1 & 2.25 & $1 \times 10^{-6}$ & 0.3 & 0.1 & 0.0055 & 0.05 & 0.3 \\
Weld metal & 1.5 & 1 & 2.25 & 0.001 & 0.3 & 0.1 & 0.008 & 0.05 & 0.2 \\
\hline
\end{tabular}

\subsection{Finite element model of $316 L N$ SS weld joint}

Figure 2 shows the finite element model used in the analyses. Figure 2(a) shows the mesh of the FE model and the loading, boundary conditions used in the analyses are shown in Figure 2(b). Abaqus FEA explicit solver is used to perform finite element calculations, and 2D plane strain elements with four-noded isoparametric formulation (CPE4R), reduced integration and nonlinear geometry are used. Loading pin is constraint from $\mathrm{x}$-displacement and fixed end pin is constraint from $\mathrm{x}$-displacement and y-displacement. Displacement control loading is performed on each specimen with load line displacement (LLD) movement equal to $9 \mathrm{~mm}$ which is applied at RP-1 as shown in Figure 2(b).

Figure 2 (a) Mesh for a CT specimen (b) Loading and boundary conditions on the CT specimen (see online version for colours)
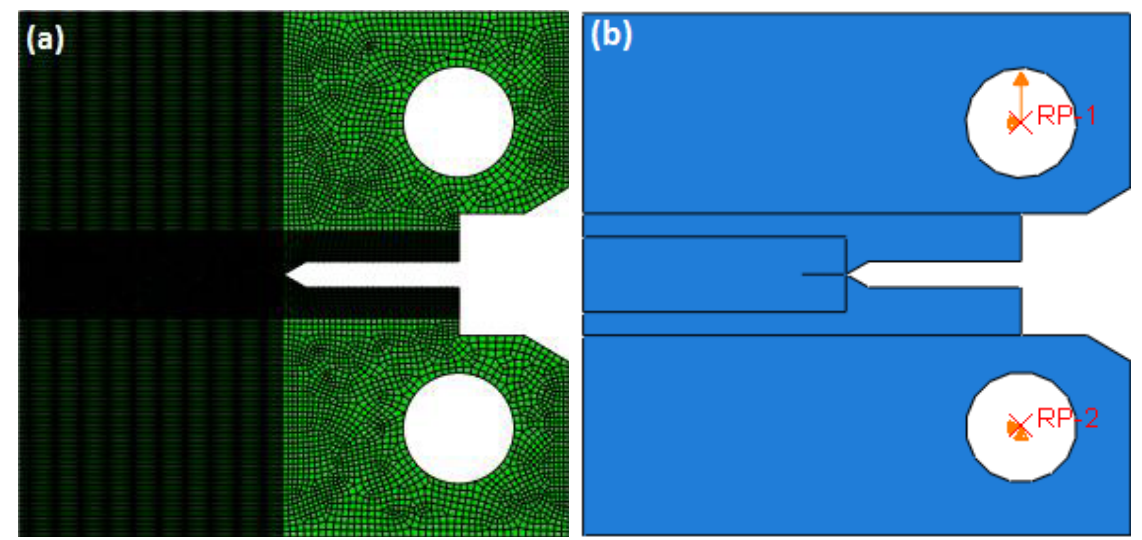

The actual crack growth path along the specimen thickness direction could not be obtained by the $2 \mathrm{D}$ analysis. It is found that the rectangular mesh element with aspect ratio equal to $2(0.05 \times 0.1)$ near the crack growth area can simulate stable crack growth with reduced oscillations (Østby et al., 2007). Hence, the mesh size of aspect ratio 2 is 
maintained near the crack growth region. To understand the fracture behaviour of the welded joints, three numerical models with different crack locations on the CT specimen are used. All specimens have the same dimensions, the loading, and boundary conditions. It is to be noted that the straight interfaces are used to model the weld interfaces in the finite element models.

\section{Numerical simulation results}

\subsection{LN SS weld joint with a central crack in WM}

The GTN parameters determined in the previous section are used to study the ductile crack growth initiation and propagation of welded 316LN SS using CT specimen of $\mathrm{a} / \mathrm{W}=0.5$. The weld width is $14 \mathrm{~mm}$ with notch and pre-crack placed at the centre of the weld. Crack opening displacement (COD) is the distance measured between the two crack faces with an increase in applied displacement at the load pin as shown in Figure 3(a). Figure 3(a) also shows the elements reached $f_{F}$ value near the crack front and these elements (also called stress free elements) explains the crack propagation phenomenon with applied displacement at the welded region using GTN damage model.

Figure 3 (a) Shows the crack propagation in the CT specimen when $f$ reaches $f_{F}$ (b) Comparison of experimental and simulated curves force vs. COD curves (see online version for colours)

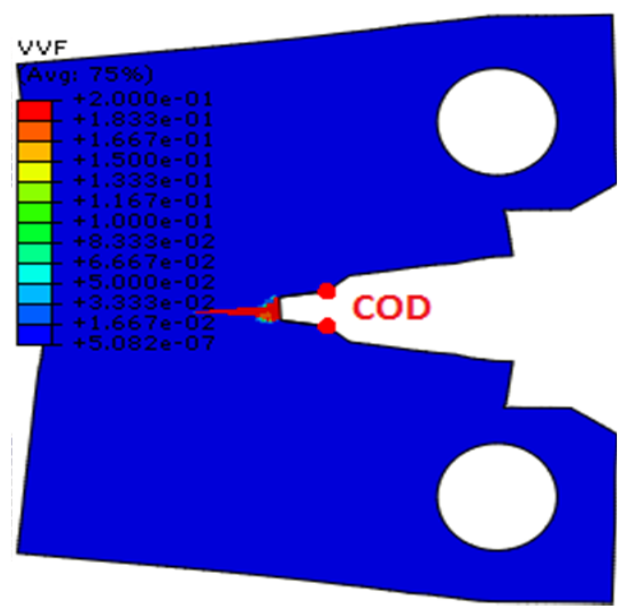

(a)

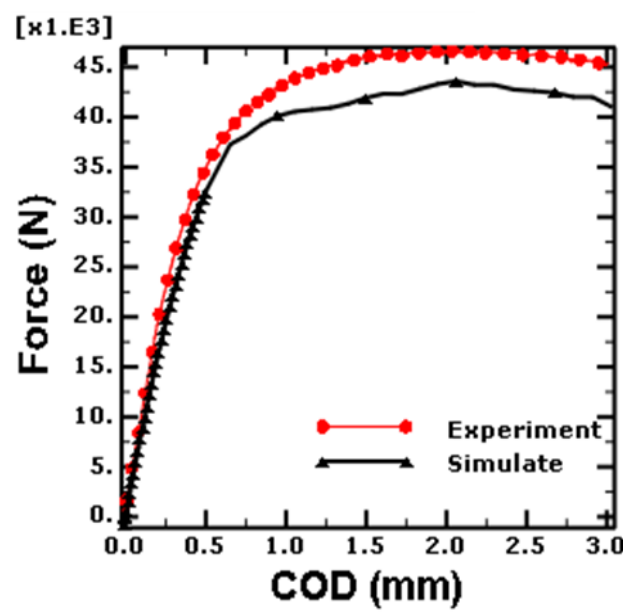

(b)

This phenomenon also gives us an easy way to calculate the change in crack length by measuring the distance from initial crack tip to the current element which reaches $f_{F}$. The obtained load vs. COD is plotted and shown in Figure 3(b). Such numerically obtained load vs. COD is compared with experimental results performed at IGCAR. This comparison shows the elastic regions of the finite element curve and experimental curve are identical and plastic region of curves are not quite identical. More numerical studies and in-situ tests are required at several regions of the weld joints to predict the crack growth resistance close to experiments. Such agreement in trend between the simulated 
and experimental results implies that the current set of GTN parameters for WM are acceptable and can be used for further prediction. Hence the evaluated GTN parameters are used for the further simulations on $316 \mathrm{LN}$ SS weld joints.

\subsection{Ductile crack growth behaviour of weld joint with different crack locations}

This part discusses the ductile crack behaviour of the weld joint with $\mathrm{a} / \mathrm{W}=0.5$ for different crack locations by observing the load vs. COD. It includes one central crack, one interface crack and two near interface cracks. BM-WM interface means that the initial crack lies at the interface of BM and WM as shown in Figure 4(a). BM-BM/WM near interface crack means that the crack lies in BM and near to BM-WM interface and $\mathrm{WM}-\mathrm{WM} / \mathrm{BM}$ near interface crack means that crack lies in the WM, and near to WM WM-BM interface as shown in Figure 4(b) and Figure 4(c) respectively.

\subsubsection{Load vs. COD for different crack location}

Specimens with different crack locations in the weld joint are shown in Figure 4. Load vs. COD curves for different crack locations are plotted and compared with WM central crack as shown in Figure 5. It is seen that the specimens with different crack locations have different load vs. COD curves and for crack locations other than WM central crack, have the very poor load-bearing capacity. The WM central crack is showing a stable crack growth propagation when compared to other crack location specimens. When COD at crack initiation obtained for different crack locations are compared, BM-WM interface crack fails very early when compared to cracks at other locations and the BM-BM/WM near interface crack shows failure much early than WM-WM/BM near interface crack.

Figure 4 Specimen with different crack locations, (a) BM-WM (b) BM-BM/WM (c) $\mathrm{WM}-\mathrm{WM} / \mathrm{BM}$

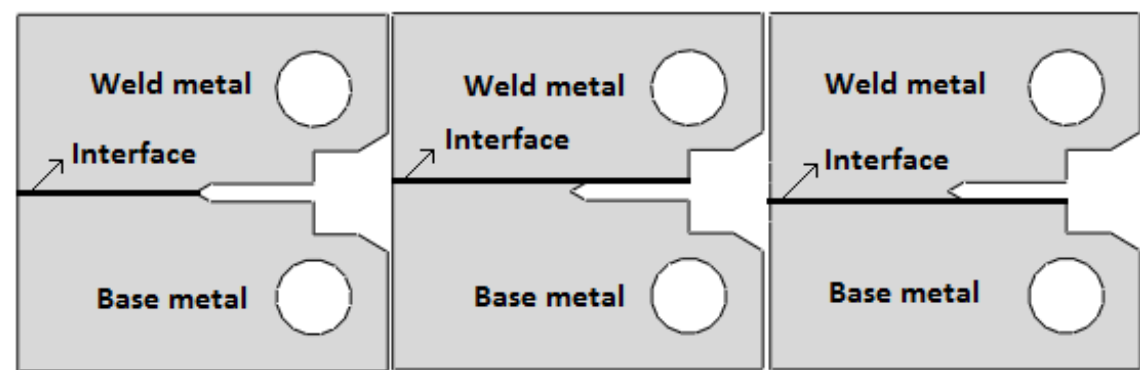

(a)

(b)

(c)

Different load vs. COD curves for the initial cracks at a different location in the weld joint may be caused by the different mechanical properties of the materials and mismatches in yield strength and plastic properties between different materials in the joint. The mismatches cause the difference in local crack tip stress and strain distribution between different materials and influences the local ductile damage and fracture process. Such mismatch influences the crack growth behaviour, and asymmetric stress and strain distribution at the crack tip can cause deviation in the crack growth path. 
Figure 5 Load vs. COD for different crack locations

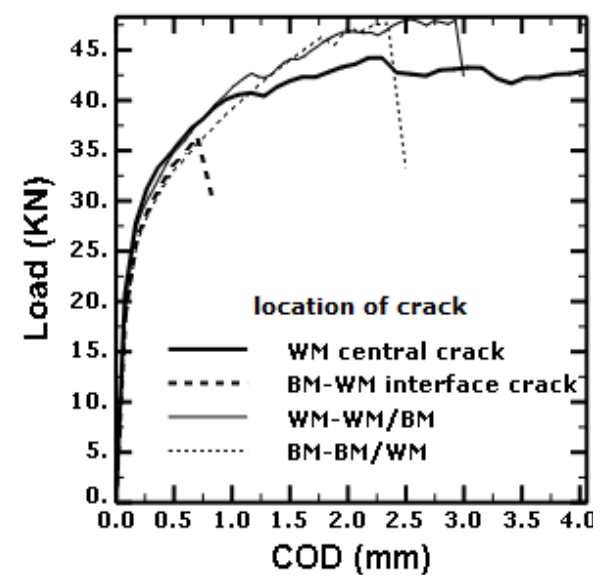

Figure 6 COD vs. change in crack length s $(\Delta a)$ for different crack locations

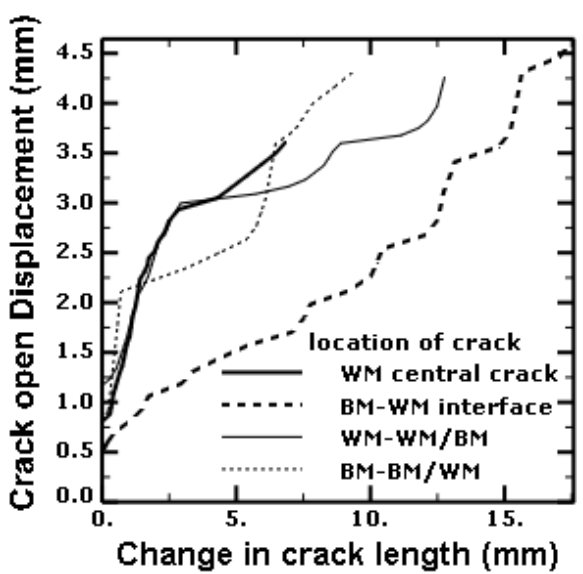

\subsubsection{COD vs. $\triangle a$ for different crack location}

COD vs. change in crack length $(\Delta \mathrm{a})$ for different crack locations are plotted and shown in Figure 6. It is seen that different crack locations highly affect the crack growth path and final crack length. It is also seen that crack initiation happens at different COD values. $\mathrm{BM}-\mathrm{WM}$ interface crack initiates at $\mathrm{COD}=0.491 \mathrm{~mm}$, and the crack length is very high. Compared to other crack location, the reduction in the slope instigated by $\mathrm{BM}-\mathrm{WM}$ interface crack is high. For BM-BM/WM and WM-WM/BM near interface cracks, initiation occurs at $\mathrm{COD}=0.81 \mathrm{~mm}, \mathrm{COD}=1.17023 \mathrm{~mm}$ respectively and for WM central crack, crack initiation occurs at $\mathrm{COD}=0.94 \mathrm{~mm}$.

From the graph, the slope and variation in crack growth of the WM-WM/BM near interface crack are compared with WM central crack. It is observed that the slope of these two specimens is not affected by the crack location. It is also seen that the crack path of WM-WM/BM deviates from WM central crack. Such deviation happens when the crack moves across the interface and starts growing inside the BM and hence had increased 
crack length $\Delta$ a equal to $12.487 \mathrm{~mm}$ when compared to WM central crack whose crack length $\Delta \mathrm{a}$ is $6.454 \mathrm{~mm}$. The BM-BM/WM near interface crack growth length $\Delta \mathrm{a}$ is equal to $9.307 \mathrm{~mm}$. It is observed that crack tip deformation, damage and cracks path can be investigated to examine the change in crack length $(\Delta a)$ and load-bearing capacity for different crack location. Such observation is further investigated and discussed in following Section 4.

\section{Discussion}

\subsection{Crack tip deformation, damage and crack growth path of $316 L N$ SS for different crack locations}

Crack tip deformation, damage and crack growth path are examined to explain the difference in load vs. COD curves and COD vs. change in crack length $(\Delta \mathrm{a})$ curves at different crack locations. To examine crack tip deformation, damage and crack growth path in the weld joint, the equivalent plastic strain (PEEQ) and VVF distributions at different displacements levels are studied for the interface crack and near interface cracks. Equivalent plastic strain (PEEQ) is defined as the history dependent accumulated plastic strain and its contours reflect the local plastic deformation at the crack tip. VVF contours show the damage distribution in the materials with an increase in load. $L L D_{1}$ represents the displacement of load pins at crack initiation and $L L D_{2}$ represents the displacement of load pins when it is equal to $9 \mathrm{~mm}$. Figure 7(a), 7(c) and 7(e) represent PEEQ contours at $L_{L} D_{1}$ and Figure 7(b), 7(e) and 7(f) represent VVF contours at $L_{L D}$. The PEEQ and VVF contours shown in Figure 7(a) and 7(b) correspond to BM-WM interface crack at two different displacement levels. From Figure 7(a), it is seen that the distribution of PEEQ is asymmetric ahead of the crack tip at $\mathrm{LLD}_{1}=1.432 \mathrm{~mm}$, and when the displacement is increased to $\mathrm{LLD}_{2}$ it is found from Figure 7(b) that the crack length $\Delta$ a reaches $17.3 \mathrm{~mm}$. The asymmetrical distribution of PEEQ and crack damage induces the crack growth path to be strictly into the BM, nearly straight, and parallel along the initial crack plane.

The distribution of PEEQ and VVF contours for the case of BM-BM/WM interface cracks at two displacements levels are shown in Figure 7(c) and 7(d). The distribution of PEEQ of the specimen is also asymmetric as shown in Figure 7(c), and plastic deformation mainly occurs in the BM. Figure 7(d) shows that the damage and crack growth also mainly takes place in the BM and the crack growth path is almost inside the $\mathrm{BM}$ but did not cross the interface and into the WM. It is seen that when the displacement is changed from $\mathrm{LLD}_{1}=2.166 \mathrm{~mm}$ to $\mathrm{LLD}_{2}$, the crack growth $\triangle \mathrm{a}$ in BM-BM/WM interface reaches $9.307 \mathrm{~mm}$. The distribution of PEEQ and VVF contours for the case of WM-WM/BM near interface crack at two different load level as shown in Figure 7(e) and Figure 7(f). The distribution of PEEQ is also asymmetric, and plastic deformation tends to develop towards BM as shown in Figure 7(e). Figure 7(f) shows that damage and crack growth take place initially in the WM. When the displacement $\mathrm{LLD}_{1}=2.879 \mathrm{~mm}$ and increases to $\mathrm{LLD}_{2}$, the crack growth length reaches $12.487 \mathrm{~mm}$, and the crack growth path crosses the interface and significantly deviates from WM into the BM causing damage to the BM. Table 1 shows the value of $f_{F}$ for $\mathrm{WM}$ and $\mathrm{BM}$ to be 0.2 and 0.3 respectively, and Figure 7(f) shows the deviation of the crack path from WM to BM when the value of $f_{F}$ changes from 0.2 to 0.3 . 
Figure 7 Shows the distribution of equivalent plastic strain and VVF for (a)-(b) BM-WM interface crack (c)-(d) BM-BM/WM near interface crack (e)-(f) WM-WM/BM near interface crack (see online version for colours)
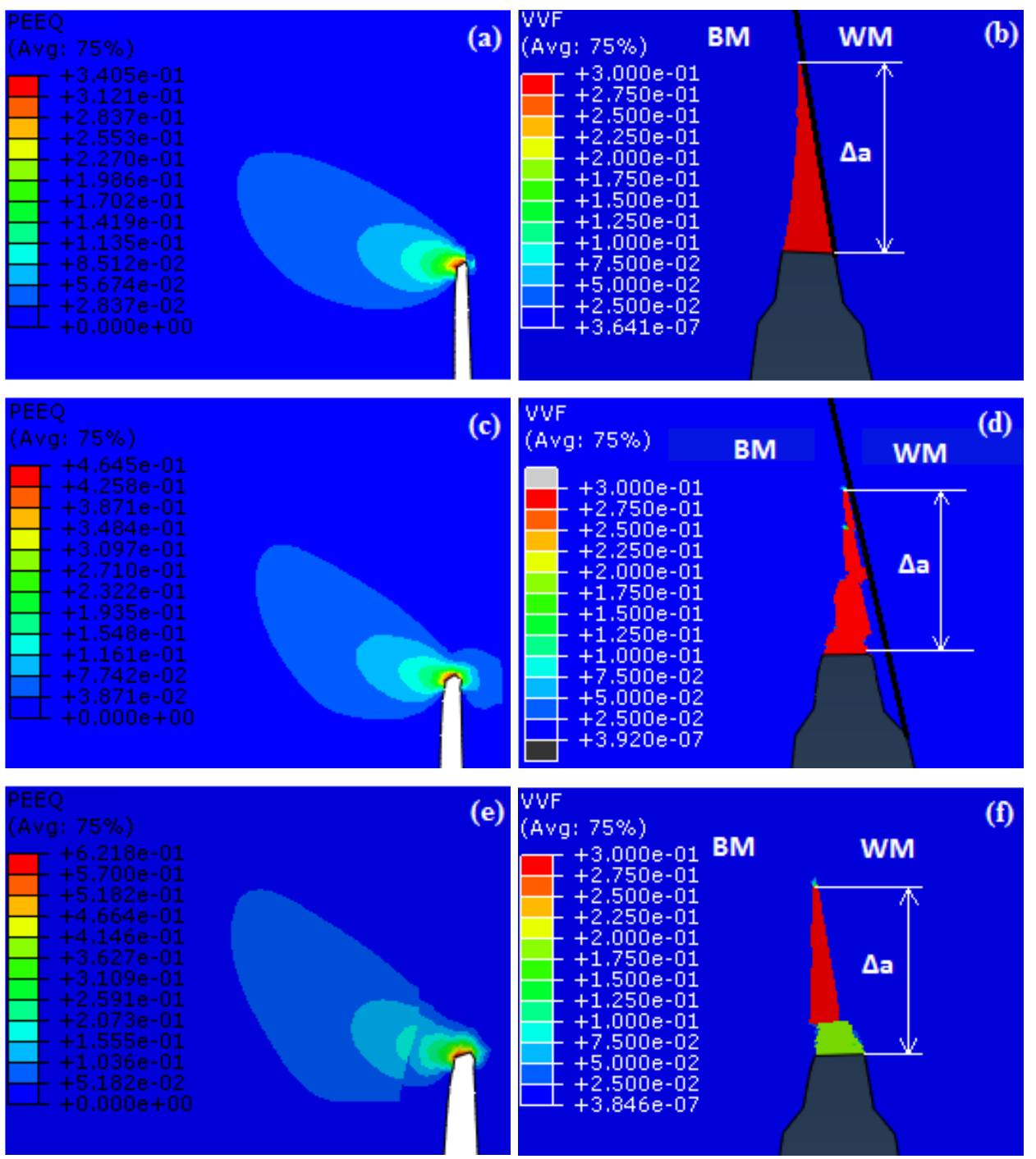

The yield stress of the $\mathrm{BM}$ is $210 \mathrm{MPa}$, and the $\mathrm{WM}$ is $410 \mathrm{MPa}$. The above results show that the crack tip deformation, damage, and crack path occur in the material with lower yield stress between the two materials of the interface. Maximum stress triaxiality observed at the crack tip also deviates crack path from the initial crack plane. BM-BM/WM near interface crack shows the deviation of the crack plane from the initial crack plane. Hence the interface crack and near interface crack growth of 316LN SS weld joint always move along the maximum stress triaxiality and into a low yield stress material. 
For interface crack, the damage happened only in the BM which is having low yield stress, and specimen failed very early with maximum crack length and minimum plastic deformation when compared to other crack locations. In WM central crack and $\mathrm{WM}-\mathrm{WM} / \mathrm{BM}$ near interface crack, the crack propagates initially in the WM, and their crack paths are identical. In WM-WM/BM, crack deviated into the BM of the interface and hence has higher crack length compared to central crack with maximum plastic deformation. In BM-BM/WM near interface crack, the crack path is into the BM and did not cross the interface. Since the crack path deviates towards the interface, the crack length is less when compared to BM-WM interface crack.

\subsection{Comparison of J-Aa resistance curve of $316 L N$ SS with other weld joints}

In previous sections, we have done a detailed study on 316LN SS weld joint to predict the crack propagation behaviour. Hence $316 \mathrm{LN}$ SS weld joint can be compared with other weld joints to predict the applicability of different weld joints at various requirements. To compare different material weld joints at elastic plastic regions, we need to evaluate $J-\Delta$ a resistance curves. $J-\Delta$ a resistance curve represents the rate of change of net potential energy with respect to crack advance for a material with an elastic-plastic response. A brief description on evaluating $J$ - $\Delta$ a resistance curve is included in Appendix 1 and is used to determine $J-\Delta$ a resistance curve of $316 \mathrm{LN}$ SS weld joint. This curve is compared with $J$ - $\Delta$ a resistance curve of SA 333 Gr.6 carbon steel, SS 309L, SS L308 and S355L. SA 333 Gr.6 carbon steel is used in the primary heat transport (PHT) piping of Indian pressurised heavy water reactor (PHWR), and numerically evaluated resistance curve is taken from Chhibber et al. (2011). SS 309L is an austenite stainless steel alloy used for its excellent oxidation resistance, creep resistance and high-temperature strength as a buttering material. SS 308L is a weld filler material which is ideal for welding types $304 \mathrm{~L}, 321$ and 347 stainless steel. Its composition is similar to SS 308 except the carbon content is held at $0.03 \%$. Such composition reduces the possibility of intergranular carbide precipitation. Numerically evaluated $J-\Delta$ a resistance curve for SS $308 \mathrm{~L}$ and SS $309 \mathrm{~L}$ is taken from dissertation report (Praveen Kumar, 2008). S355NL is a structural steel, and its weldments are used widely in building the wind-powered tower tube or the floating support structures for offshore wind turbines and its numerically evaluated resistance curve is taken from Tu et al. (2012). In this paper, numerical evaluation of $J-\Delta$ a resistance curve for all weld joints is performed using experimental procedure specified in various versions of ASTM E1820.

$J-\Delta$ a resistance curves of weld joints made of 316LN SS, SA333 Gr.6, SS 309L, SS 308L and S355NL are compared and shown in Figure 8. The change in crack length $(\Delta \mathrm{a})$ is truncated to $2.5 \mathrm{~mm}$ to compare the $J$ value at crack initiation and initial slope of $J-\Delta \mathrm{a}$ between different material weld joints. From the graph, 316LN SS weld joint $J$ value at crack initiation and initial slope of the curve is nearly same as weld joint SA 333 Gr.6, but the area under $J-\Delta$ a resistance curve is high for $316 \mathrm{LN}$ SS weld joint. Hence energy required to propagate crack to $\Delta \mathrm{a}=2.5 \mathrm{~mm}$ is high for 316LN SS weld joint. Moreover, SS 309L and SS 308L stainless steel material almost exhibit similar crack growth resistance behaviour for a given change in crack length. From the graph, S355NL has very less crack growth resistance. Hence from this study, the crack growth resistance of $316 \mathrm{LN}$ SS is higher than other material weld joints. 
Figure 8 Comparison of $J-\Delta$ a resistance curves of $316 \mathrm{LN} \mathrm{SS}$ and other similar metal welded joints

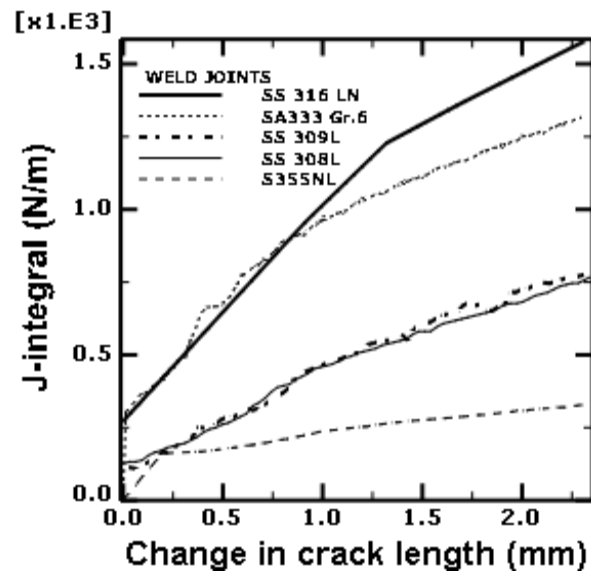

\section{Conclusions}

A finite element analysis is performed on the CT specimen made of 316LN SS BM and WMs to predict the specimen behaviour for various crack geometries in CT specimens. Geometric parameters like different crack locations within the WM specimens are used to predict and study the fracture behaviour of the weld joint. GTN damage model is used to predict the material response in the numerical simulations.

GTN parameters for WM are found numerically from tensile and CT specimens and verified with experimental results by comparing load vs. COD curves of CT specimen with experimental results. This general agreement implies that the current set of GTN parameters for WM can be used for further predictions. It is possible to have more than one set of GTN damage parameters to predict the material behaviour of the weld joint 316LN SS.

Load vs. COD curves for the different crack location are compared, and it is seen that crack behaviour is completely dependent on initial crack location along the width of the weld and central crack is more stable compared to interface cracks and near interface cracks. The crack lying at the interface is very unstable and grows fast with a small change in loads when compared with near interface cracks and central cracks. Near interface cracks deviate from the initial crack plane but cross the interface depending on yield stress of both the materials at the interface. Therefore, it is concluded that interface cracks tend to always grow into the soft material and near interface crack tends to lean towards the soft material side following the maximum stress triaxiality and grows across the interface and into the soft material.

The COD vs. change in crack length $(\Delta \mathrm{a})$ curves for the different crack location is compared to examine individual crack growth behaviour with applied loads. It is observed that the interface crack has highest crack growth and the central crack has minimum crack growth. By observing near interface crack propagation behaviour, crack initiation also affects the change in crack length $(\Delta \mathrm{a})$. It is also observed that micromechanical model like GTN model is successful in predicting the fracture 
behaviour of the material weld joint by considering the local phenomenon happening at the failure. Hence micromechanical models can provide more information about crack initiation, crack growth path, failure of the specimen independent of the geometry and loading constraints.

Different material weld joints are compared with $316 \mathrm{LN}$ SS using numerically obtained $J-\Delta$ a resistance curves evaluated using an experimental procedure to predict the applicability for various requirements. The choice of material for weld joint is highly dependent on the application. The fracture toughness observed in 316LN SS is very high and hence this material is chosen as a primary material in designing nuclear power plants. Better procedures like energy domain integral (Shih et al., 1986; Moran and Shih, 1987) and virtual crack extension methodologies (DeLorenzi, 1982) can be used to evaluate fracture toughness of the welded specimens using FEM analysis. Such procedures can be used to construct fracture resistance curves and compared with numerically evaluated fracture resistance curves using ASTM procedures to observe differences between the curves, if any.

\section{References}

Besson, J. et al. (2004) Local Approach to Fracture, p.298, Ecole des Mines de Paris, Paris.

Betegón, C. and Peñuelas, I. (2006) 'A constraint based parameter for quantifying the crack tip stress fields in welded joints', Engineering Fracture Mechanics, Vol. 73, No. 13, pp.1865-1877.

Chhibber, R., Biswas, P., Arora, N., Gupta, S.R. and Dutta, B.K. (2011) 'Micromechanical modelling of weldments using GTN model', International Journal of Fracture, Vol. 167, No. 1, pp.71-82.

Clausmeyer, H., Kussmaul, K. and Roos, E. (1991) 'Influence of stress state on the failure behaviour of cracked components made of steel', Appl. Mech. Rev., Vol. 44, No. 2, p.77.

DeLorenzi, H.G. (1982) 'On the energy release rate and the J-integral for 3D crack configurations', International Journal of Fracture, Vol. 19, No. 3, pp.183-193.

Faleskog, J., Gao, X. and Shih, C.F. (1998) 'Cell model for nonlinear fracture analysis I. Micromechanics calibration', International Journal of Fracture, Vol. 89, No. 4, pp.355-373.

Ganesh Kumar, J., Vijayanand, V.D., Nandagopal, M. and Laha, K. (2015) 'Evaluation of variation of tensile strength across 316LN stainless steel weld joint using automated ball indentation technique', Materials at High Temperatures, Vol. 32, No. 6, pp.619-626.

Giglio, M., Fossati, M., Lumassi, D. and Manes, A. (2013) 'Use of numerical simulations in damage assessment due to high velocity impacts', International Journal of Materials and Structural Integrity, Vol. 7, No. 4, pp.215-231.

Gurson, A.L. (1977) 'Continuum theory of ductile rupture by void nucleation and growth: part I yield criteria and flow rules for porous ductile media', Journal of Engineering Materials and Technology, Vol. 99, No. 1, pp.2-15

Hutchinson, J.W. (1968) 'Singular behaviour at the end of a tensile crack in a hardening material', Journal of the Mechanics and Physics of Solids, Vol. 16, No. 1, pp.13-31.

Kami, A., Dariani, B.M., Vanini, A.S., Comsa, D.S. and Banabic, D. (2015) 'Numerical determination of the forming limit curves of anisotropic sheet metals using GTN damage model', Journal of Materials Processing Technology, Vol. 216, pp.472-483.

Kirk, M.T. and Dodds, R.H. (1993) 'The influence of weld strength mismatch on crack-tip constraint in single edge notch bend specimens', International Journal of Fracture, Vol. 63, No. 4, pp.297-316. 
Kocak, M. and Es-Souni, M. (1989) 'Microstructure and weld metal matching effects on heat affected zone toughness', Proc. 8th Intn. Conference, Offshore Mechanics \& Arctic Engng, Vol. III, p.623.

Kumar, P. (2014) 'An overview of welding and fabrication aspects during manufacture of nuclear reactor components for $500 \mathrm{MWe}$ prototype fast breeder reactor', Nucl. India, Vol. 56, Nos. $1-3$, pp.1-14.

Kumar, V., German, M.D. and Shih, C.F. (1981) Engineering Approach for Elastic-Plastic Fracture Analysis (No. EPRI-NP-1931), Corporate Research and Development Dept., General Electric Co., Schenectady, NY, USA.

Michiba, K., Hiramatsu, H., Hasegawa, H., Matsumara, H. and Toyoda, M. (1994) 'An experimental study on the behaviour of stable crack growth in heterogeneity', in Proceedings of the 2nd Workshop on Constraint Effects on the Structural Performance of Welded Joints, Osaka University.

Moran, B. and Shih, C.F. (1987) 'A general treatment of crack tip contour integrals', International Journal of Fracture, Vol. 35, No. 4, pp.295-310.

Muránsky, O., Hamelin, C.J., Patel, V.I., Luzin, V. and Braham, C. (2015) 'The influence of constitutive material models on accumulated plastic strain in finite element weld analyses', International Journal of Solids and Structures, September, Vols. 69-70, pp.518-530.

Nègre, P., Steglich, D. and Brocks, W. (2005) 'Crack extension at an interface: prediction of fracture toughness and simulation of crack path deviation', International Journal of Fracture, Vol. 134, No. 3, pp.209-229.

O'dowd, N.P. and Shih, C.F. (1991) 'Family of crack-tip fields characterized by a triaxiality parameter - I. Structure of fields', Journal of the Mechanics and Physics of Solids, Vol. 39, No. 8, pp.989-1015.

O'dowd, N.P. and Shih, C.F. (1992) 'Family of crack-tip fields characterized by a triaxiality parameter - II. Fracture applications', Journal of the Mechanics and Physics of Solids, Vol. 40, No. 5, pp.939-963.

Østby, E., Thaulow, C. and Zhang, Z.L. (2007) 'Numerical simulations of specimen size and mismatch effects in ductile crack growth - part I: tearing resistance and crack growth paths', Engineering Fracture Mechanics, Vol. 74, No. 11, pp.1770-1792.

Praveen Kumar, P. (2008) Determination of Fracture Characteristics of Nuclear Weld Using Modified GTN Model, Master's Degree thesis, Thapar University [online] http://dspace.thapar. edu:8080/jspui/handle/10266/679 (accessed 1 September 2017).

Qian Guo, Q., Lu, F., Cui, H., Yang, R., Liu, X. and Tang, X. (2015) 'Modelling the crack propagation behavior in $9 \mathrm{Cr} / \mathrm{CrMoV}$ welds', Journal of Materials Processing Technology, December, Vol. 226, pp.125-133.

R6 (1998) Assessment of the Integrity of Structural Containing Defects, British Energy, R/H/R6 Revision 3.

Rakin, M., Gubeljak, N., Dobrojević, M. and Sedmak, A. (2008) 'Modelling of ductile fracture initiation in strength mismatched welded joint', Engineering Fracture Mechanics, Vol. 75, No. 11, pp.3499-3510.

Rice, J. and Rosengren, G.F. (1968) 'Plane strain deformation near a crack tip in a power-law hardening material', Journal of the Mechanics and Physics of Solids, Vol. 16, No. 1, pp.1-12.

Rice, J.R., Paris, P.C. and Merkle, J.G. (1973) 'Some further results of J-integral analysis and estimates', ASTM STP 536, pp.231-245, American Society for Testing and Materials, Philadelphia, PA.

Rousselier, G. (1987) 'Ductile fracture models and their potential in local approach of fracture', Nuclear Engineering and Design, Vol. 105, No. 1, pp.97-111.

Samal, M.K., Balani, K., Seidenfuss, M. and Roos, E. (2009) 'An experimental and numerical investigation of fracture resistance behaviour of a dissimilar metal welded joint', Proceedings of the Institution of Mechanical Engineers, Part C: Journal of Mechanical Engineering Science, Vol. 223, No. 7, pp.1507-1523. 
Schuler, X., Blind, D., Eisele, U., Herter, K.H. and Stoppler, W. (1994) 'Fracture mechanics evaluation of cracked components with consideration of multiaxiality of stress state', Nuclear Engineering and Design, Vol. 151, Nos. 2-3, pp.291-305.

Shih, C.F., Moran, B. and Nakamura, T. (1986) 'Energy release rate along a three-dimensional crack front in a thermally stressed body', International Journal of Fracture, Vol. 30, No. 2, pp.79-102.

Standard, A.S.T.M. (2001) Standard Test Method for Measurement of Fracture Toughness, ASTM, E1820-01, pp.1-46.

Tu, H., Schmauder, S. and Weber, U. (2012) 'Numerical study of electron beam welded butt joints with the GTN model', Computational Mechanics, Vol. 50, No. 2, pp.1-11.

Tvergaard, V. and Needleman, A. (1984) 'Analysis of the cup-cone fracture in a round tensile bar', Acta Metallurgica, Vol. 32, No. 1, pp.157-169.

Vijayanand, V.D., Kumar, J.G., Parida, P.K., Ganesan, V. and Laha, K. (2017) 'Studies on creep deformation and rupture behavior of $316 \mathrm{LN}$ SS multi-pass weld joints fabricated with two different electrode sizes', Metallurgical and Materials Transactions A, Vol. 48, No. 2, pp.706-721.

Wang, H.T., Wang, G.Z., Xuan, F.Z. and Tu, S.T. (2011) 'Numerical investigation of ductile crack growth behavior in a dissimilar metal welded joint', Nuclear Engineering and Design, Vol. 241, No. 8, pp.3234-3243.

Williams, M.L. (1957) 'The bending stress distribution at the base of a stationary crack', J. Appl. Mech., Vol. 24, pp.109-114.

Zhang, Z.L., Hauge, M. and Thaulow, C. (1996) 'Two-parameter characterization of the near tip stress fields for a bi-material elastic-plastic interface crack', International Journal of Fracture, Vol. 79, No. 1, pp.65-83.

Zhang, Z.L., Hauge, M. and Thaulow, C. (1997a) 'The effect of T stress on the near tip stress field of an elastic-plastic interface crack', in ICF 9, Sydney, Australia.

Zhang, Z.L., Thaulow, C. and Hauge, M. (1997b) 'Effects of crack size and weld metal mismatch on the has cleavage toughness of wide plates', Engineering Fracture Mechanics, Vol. 57, No. 6, pp.653-664.

\section{Appendix 1}

The $J$-integral can be evaluated numerically along a contour surrounding the crack tip for both linear and nonlinear problems. DeLorenzi (1982) formulated the virtual crack extension approach in terms of finite element stiffness and displacements matrices and by considering the energy release rate of a continuum. The energy domain integral methodology formulated by Shih et al. (1986) and Moran and Shih (1987) is also used to numerically evaluate $J$-integral. This approach is very similar to the virtual crack extension method. In this study, an experimental testing procedure in ASTM E1820-17 is used to evaluate $J$-integral and $J$ - $\Delta$ a resistance curve for $316 \mathrm{LN}$ SS. Since resistance curves of the weld joints taken from the literature are using similar procedure to compare with ASTM experiments, a similar procedure is implemented to find resistance curve of 316LN SS to compare it with other material weld joints.

For determining $J-\Delta$ a resistance curve, finite element models are loaded at different displacements levels. From FE model and analysis, the parameters like crack length $(a)$, peak load $(P)$, the plastic area under the force vs. LLD $\left(A_{p l}\right)$, the plastic part of load-line displacement (LLD) $(v)$, ligament length $(b)$ are determined. The width $(W)$ of the specimen is $50 \mathrm{~mm}$. The initial crack length and ligament size is $25 \mathrm{~mm}$. Concerning 
ASTM E1820-17, single-specimen test procedure, and formulas for CT specimen are used to determine the crack growth resistance curve ( $J$ - $\Delta$ a curve) using different sets of loading points and corresponding crack lengths.

The formulas used for evaluating $J$ values at corresponding simulation step $i$ are given below:

$$
\begin{aligned}
& K=\frac{P_{(i)}}{B W^{1 / 2}} f\left(\frac{a_{(i)}}{W}\right) \\
& f(a / W) \\
& =\frac{\left\{\left(2+\frac{a}{W}\right)\left[0.886+4.64\left(\frac{a}{W}\right)-13.32\left(\frac{a}{W}\right)^{2}+14.72\left(\frac{a}{W}\right)^{3}-5.6\left(\frac{a}{W}\right)^{4}\right]\right\}}{\left(1-\frac{a}{W}\right)^{3 / 2}} \\
& J_{(i)}=\frac{\left(K_{(i)}\right)^{2}\left(1-\vartheta^{2}\right)}{E}+J_{p l(i)} \\
& J_{p l(i)}=\left[J_{p l(i-1)}+\left(\frac{\eta_{(i-1)}}{b_{(i-1)}}\right) \frac{A_{p l(i)}-A_{p l(i)}}{B_{N}}\right] *\left[1-\gamma_{(i-1)} \frac{a_{(i)}-a_{(i-1)}}{b_{(i-1)}}\right]
\end{aligned}
$$

where the $\eta_{(i-1)}=2.0+0.522 b_{(i-1)} / W, \gamma_{(i-1)}=1.0+0.76 b_{(i-1)} / W, b_{(i-1)}$ is the ligament size at point $(i-1)$ and is calculated as the difference between specimen width $(W)$ and crack size $a_{(i-1)}$ at load simulation step $i . K_{(i)}$ is stress intensity factor calculated using equation (A1), $\vartheta$ is Poisson's ratio, $E$ is Young's modulus of the material. The $a_{(i)}-a_{(\mathrm{i}-1)}$ is the increment in crack length between two constant displacement points $(i)$ and $(i-1)$ as shown in Figure A1. The $A p l_{(i)}-A p l_{(i-1)}$ is the increment of plastic area under the force versus LLD records.

Figure A1 Shows the definition of area $\left(A_{p l}\right)$ for $J$ calculation, peak load $(P)$, plastic part of LLD $\left(v_{p l}\right)$, simulation step $(i)$

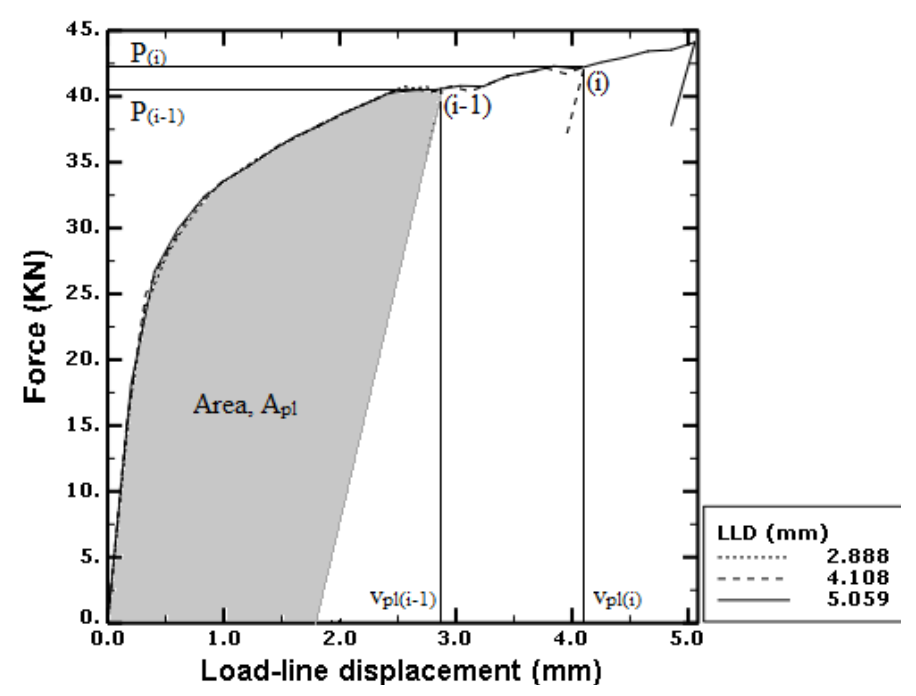


Table A1 Values evaluated for each event (i)

\begin{tabular}{lcccccc}
\hline Event $(i)$ & $P[N]$ & $v[\mathrm{~mm}]$ & $a[\mathrm{~mm}]$ & $\Delta a[\mathrm{~mm}]$ & $K\left[\mathrm{MPa}-\mathrm{m}^{1 / 2}\right]$ & $J\left[\mathrm{KJ} / \mathrm{m}^{2}\right]$ \\
\hline 1 & 40,619 & 2.450 & 25.465 & 0.465 & 129.004 & 621.019 \\
2 & 42,297 & 3.652 & 25.910 & 0.910 & 138.172 & 954.455 \\
3 & 44,118 & 4.551 & 26.319 & 1.319 & 147.975 & $1,227.678$ \\
4 & $43,527.1$ & 5.030 & 26.708 & 1.708 & 149.777 & $1,369.713$ \\
5 & $44,298.9$ & 5.709 & 27.309 & 2.309 & 158.721 & $1,576.840$ \\
6 & $43,326.4$ & 6.552 & 28.113 & 3.113 & 164.170 & $1,840.354$ \\
7 & $42,597.2$ & 7.861 & 29.099 & 4.099 & 173.411 & $2,234.359$ \\
\hline
\end{tabular}

From the load vs. LLD, find the plastic area, $A p l_{(i)}$ under load vs. LLD, peak load $\left(P_{(i)}\right)$ and the plastic part of LLD $\left(v_{(i)}\right)$ as shown in Figure A1. Change in crack length $\left(\Delta a_{i}\right)$ at each displacement point is the distance as the projection of the actual crack growth path down to the initial crack plane for simulation step $i$. Table A1 shows the value of peak load $(P)$, the plastic part of LLD $(v)$, current crack extension length $(a)$, change in crack length $(\Delta \mathrm{a})$, stress intensity $(K), J$-integral $(J)$ at different displacement events. The evaluated data is used to plot $J-\Delta$ a resistance curve for $316 \mathrm{LN} \mathrm{SS}$. 